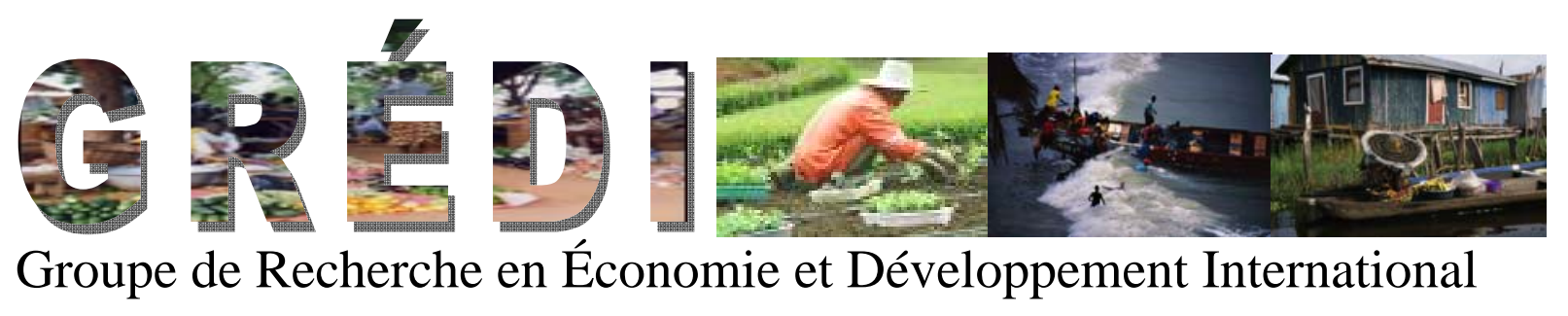

Cahier de recherche / Working Paper

07-18

The Impact of Switching Costs on Vendor Financing

M. Martin Boyery

Karine Gobert 


\title{
The Impact of Switching Costs on Vendor Financing*
}

\author{
M. Martin Boyer ${ }^{\dagger}$ and Karine Gobert ${ }^{\ddagger}$
}

August 20, 2007

\begin{abstract}
Empirical studies point to trade credit as an important continuing source of short term financing for small and medium-sized enterprises. We show that vendor financing appears in equilibrium as the result of repeated trade interactions between a buyer and a supplier when changing supplier is costly. The supplier is then able to extract a periodic rent from the buyer. The presence of switching costs is not, however, detrimental to the buyer because competition between suppliers for this rent forces them to offer a rebate before the relationship is initiated. This sequence of a rebate followed by high prices is similar to a long term financing structure. The role of switching costs is similar to that of a precommitment device that allows the buyer to borrow a limited amount of capital from the supplier in the first period and to roll over the debt until the end of the relationship. In the case of small business owners who have difficulty accessing financial markets, our model suggests that switching costs allows them to smooth their dividend income, albeit inefficiently, by using vendor financing.
\end{abstract}

Classification JEL : D92, D86, C73

Keywords : Trade credit, financing of the firm, commitment, self-enforcing contracts.

*This research was made possible by a grant from the Social Science and Humanities Research Council of Canada. The continuing financial support of CIRANO is also appreciated.

${ }^{\dagger}$ CEFA Professor of Finance and Insurance, HEC Montréal, Université de Montréal, 3000 chemin de la Côte-Sainte-Catherine, Montréal QC H3T 2A7 CANADA; and Cirano, 2020 University Ave, 25th floor, Montréal QC, H3A 2A5 CANADA; martin.boyer@hec.ca

${ }^{\ddagger}$ Faculté d'administration and GREDI, Université de Sherbrooke, 2500 Boulevard de l'Université, Sherbrooke, QC J1K 2R1 Canada; and Cirano, 2020 University Ave., 25th floor, Montréal, QC H3A 2A5. karine.gobert@usherbrooke.ca; (t) 819-821-8000 \#62315; (f) 819-821-7934. 


\section{Introduction}

Vendor financing, also known as trade credit, occurs between two corporations that agree that the payment for a good they exchange will be made after delivery of said good. One corporation is therefore a debtor to the other in the period of time between the delivery and payment. Trade credit is an important source of firm financing, medium and especially so for small and medium-sized enterprises. Cuñat (2007) estimates that trade credit represents $17 \%$ of the average medium sized British firm's asset and $40 \%$ of its debt financing. He also reports that in the United States, trade credit represents $18 \%$ of total assets and $35 \%$ of total debt for small and medium sized enterprises. These numbers are similar to those found by Rajan and Zingales (1995) where they find that accounts payable represented an average of $14 \%$ of the book value of assets of G7 corporations.

Another way to display the economic importance of trade credits (see $\mathrm{Ng}$ et al., 1999) is that trade credit represented, in any given year during the nineties, 1.5 trillion dollars of the book value of assets of American firms. Short term debt issuance in the form of trade credits dwarfs the combined value of public debt and equity issuance in any given year by a factor of 2.5. For macroeconomists, the best image we can think of to convey the economic importance of trade credits is that it is 1.5 times the size of M1, the primary money supply. Trade credit is clearly an important source of financing.

Abstracting from the pure short-term debt financial aspect of vendor financing, there are business specific value maximizing explanations for parties to delay payments for a good. For instance, the customer may want to assess the real value of the delivered good (Long, Malitz and Ravid, 1993) before making the payment. Another possibility is that the trade credit terms can signal product quality (Emery and Nayar, 1998). Trade credit may also be part of the supplying firm's marketing strategy; by offering credit to customers faced with a negative liquidity shock, a supplier is able to initiate or maintain beneficial long term relationships with its client. Moreover, offering trade credit can be a way to price discriminate (Brennan, Maksimovic and Zechner, 1988) or to minimize transactions costs (Ferris, 1981).

From a financial viewpoint, the primary research question related to trade credits in the past twenty years has been to explain why supplier firms would substitute to banks in extending credit to other firms. Cuñat (2007) sees trade credit as a substitute for bank loans. He finds that trade credit is used when all other forms of credit have been exhausted. We situate on this side because we model the behavior of a firm that has no access to credit. 
The buyer uses the periodic transfers with the supplier to obtain a timing of dividends that he could not otherwise attain. Other empirical studies also found evidence that trade credit substitute to bank credit for credit constrained firms. For instance Petersen and Rajan (1997) and Danielson and Scott (2000), using the database on small and medium-sized entreprises in the United States, find that small firms are most likely to use trade credit if they are constrained on credit. Niskanen and Niskanen (2006) obtain a similar result using firm data from Finland. They all support the substitution theory that firms use trade credit only when other sources of borrowing have been exhausted.

For Demirgüç-Kunt and Maksimovic (2001), however, trade credit should be seen as a complement to bank credit rather than a substitute. Using cross country comparison of the use of trade credit, they find evidence that trade credit is more important in countries with a better financial system. Hence, it must be that financially sound firms obtain credit from banks, a credit they extend themselves to less healthy firms. This adds efficiency to the financial system when suppliers have an informational advantage to lend to their clients. For instance, suppliers may have a better information about their client's creditworthiness (Smith, 1987; Biais and Gollier, 1997; Jain, 2001), or they may be less vulnerable to cash diversion (Burkart and Ellingsen, 2004). Default is also less costly for suppliers since they can liquidate the collateral (the supplied good) at better terms than a bank (Frank and Maksimovic, 1998; Santos and Longhofer, 2003). Using data from U.S. small businesses Elliehausen and Wolken (1993) find support for the theory that trade and bank credit are complements. Similarly, Burkart, Ellingsen and Giannetti (2006) find empirical evidence that receiving trade credit conveys favorable information that helps firms obtain bank credit.

A leading explanation as to why trade credit is so popular is that suppliers are better able to enforce payments than financial institutions when there is a future value to the trade relationship for the client. If for instance suppliers can credibly threaten to stop the trading relationship with their client in the event of non-payment - a threat that financial institutions cannot make by definition - it becomes easier for suppliers to extend credit to firms. This is the case when the specificity of the good supplied makes the supplier costly to replace. Burkart, Ellingsen and Giannetti (2006) find empirical evidence that the use of trade credit is linked to the characteristics of the traded good. Not only are firms selling differentiated products offering more trade credit (measured by receivable/sales), they also find that firms that buy a larger fraction of differentiated products are more likely to be offered trade credit. 
An interesting feature of Cunat (2007) is that the total amount of trade credit offered is a function of the maximum repayment that the supplier can enforce. Having a negotiating power, the supplier can lend even if the client does not have enough collateral. Put differently, because of its position of power with respect to the client, the supplier is able to lend more than what a bank would agree to. Our model is built on this theory that enforcement power is central to vendor financing. Suppliers provide financing when the buyer must support a cost of adjustment to a supplier's input so that changing supplier is costly for the buyer. In contrast to previous literature that concentrates mostly on short term relationships, our approach has the distinct advantage of combining short term financing with long-term relationships between business partners to explain long term trade relationships between suppliers and clients. Our theory therefore focuses on the timing of transfers in an economy where the supplier has a negotiation power but no market power. We generate vendor financing as a consequence of trade relationships instead of imposing a relationship where the client requires credit to operate his project. In a repeated buyer/supplier relationship with no bank and in the presence of imperfect contracting between the parties, we show how vendor financing appears in the equilibrium sequence of transfers.

We model the relationship between a large risk neutral deep-pocket supplier with access to perfect financial markets and a small risk averse buyer who is credit constrained and is therefore not indifferent to the timing of his income. Although it is true that size may not be the only determinant of credit constraints, studies of small business finance ${ }^{1}$ find that most small businesses are subject to credit rationing and that they have an imperfect access to financial markets. The risk aversion inherent to the buyer's concave value function also implies that, in a dynamic setting, he has a preference for smoothing his consumption over time. $^{2}$ This behavior illustrates that the buyer cannot use lending and borrowing at no cost on the financial market in order to eliminate fluctuations in his periodic dividend. In a small enterprise, the owner's consumption depends on the dividend generated by his business. He then approaches trading partners with this risk averse behavior, meaning that he is willing to use any long term relationship to obtain further smoothing of his dividend. The small

\footnotetext{
${ }^{1}$ See for instance the 1994 report by the US Small Business Administration

${ }^{2}$ Although there are multiple theoretical reasons why even a large firm could act as if it were risk averse, we prefer to distance ourselves from this debate at the moment. For those interested as to why large corporations could be contrued as risk averse entities, we suggest to examine Graham and Smith (1999) and Graham and Rogers (2002) for reasons associated with the convexity of the tax schedule, Smith and Stulz (1985) and Nance et al. (1993) for bankruptcy costs, DeMarzo and Duffie (1995) for signalling of managerial quality, and Boyer et al. (2005) for coordination problems between managers.
} 
business owner's problem is then to find a partner who is interested in offering him a tool that allows for dividend smoothing. This is what adjustment costs offer in our case.

In line with the contract theory result that it is in the agents' best interest ex-ante to find a way to credibly commit to their contractual relationship, our model introduces switching costs that induce the buyer to enter a relationship in which he is held up by the supplier. The hold up situation acts as a precommitment mechanism that enables the relationship to last for more than one period. The supplier can then safely make value increasing transfers to the client at the beginning of the relationship. As the result of the transfers' particular timing between the supplier and the client, vendor financing emerges as a byproduct of a contract imperfection.

Cuñat (2007) also introduces an insurance relationship in his model where the buyer seeks financing to avoid bankruptcy in periods where a bad liquidity shock occurs. He shows that the trade credit pattern of transfers incorporates risk sharing at a premium. We abstract from this issue by removing any and all uncertainty in the buyer's income. We can thus generate vendor financing with the supplier's enforcement power solely through switching costs and competition between suppliers. Adding uncertainty on the buyer's income would of course generate an insurance component into the transfer price with no additional insight on the financing per se. our contribution is thus to present an extremely simplified contract where adjustment costs are sufficient to make a form of incomplete long term financing through trade credit self enforceable.

The paper is structured as follows. In the next section we present the basic model and the first best solution to trade relationships. We also show how trade credit appears at the equilibrium of the self enforcing relationship with switching costs. In the last Section, we discuss how this timing of payments can be turned into financing for any first period investment.

\section{The basic model with no investment}

Suppose a firm that has a widget-producing project that will last for $T+1$ periods denoted $t=0 \cdots T$. This firm, which we shall refer to as the buyer for the remainder of the paper, produces in each period widgets that can be sold on the competitive market at some unit price $p$. The buyer's production function displays constant marginal returns and his marginal 
cost is $c$ for all levels of production. Without loss of generality we normalize production to one unit.

To produce this widget in every period, the buyer must acquire one unit of an intermediary good for which there are $N$ potential suppliers. As suppliers compete in prices, $N$ does not have to be large to entail competition among sellers. Every supplier faces a constant marginal cost of producing the intermediary good (the competitive reserve price) equal to $\gamma$. In every period, the contract between the buyer and one of the suppliers specifies a transfer $\pi_{t}$ from the buyer to the supplier for the delivery of one unit of the intermediary good.

Suppliers provide intermediary goods that are differentiated. Hence, by choosing a particular supplier the buyer must make some costly adjustments to his production process. The buyer's assets are, therefore, specific to the intermediary good used. We denote by $a$ the adjustment cost to the input involved. This cost must be borne by the buyer each time he changes his production line to fit with one supplier's particular intermediary good. In other words, changing supplier entails a switching cost for the buyer equal to $a$.

Adjustment costs imply that the buyer is held up in the relationship with a supplier. That is, once he has chosen a supplier and adapted his production to the supplier's differentiated product in a given period, the buyer can be made to pay a price higher than the market price for the intermediary good since his negotiation power is reduced by the perspective of having to pay a to switch to another supplier. Under usual circumstances this hold-up situation should be harmful for the buyer; that this is not the case in our paper, however.

We focus the paper on a relationship between the owner of a small or medium size business and a larger supplier. A small business is characterized by two elements. Firstly, it has one (or a few) owner whose wealth is mainly invested in the firm and who has therefore an undiversified portfolio of assets. Secondly, it has a constrained access to financial markets so that transfering revenue from period to period or accross states of the world is impossible. This gives our buyer a risk averse behavior so that he values smooth income (represented here by the dividend stream) over time. ${ }^{3}$ As a result we shall model the firm as having a concave value function to display aversion towards risky income and strong preferences for income smoothing.

Let us define $V\left(d_{t}\right)$ as the per period value of the buyer over the dividend $d_{t}$ generated by the production and selling of the widget. We have $V^{\prime}\left(d_{t}\right)>0$ and $V^{\prime \prime}\left(d_{t}\right)<0$ with

\footnotetext{
${ }^{3}$ See Stulz (1984), Campbell and Kracaw (1987), and DeMarzo and Duffie (1995).
} 
$V(0)=0$. As a large corporation with well diversified owners, the supplier has a perfect access to the financial market so that she can transfer income across periods at no cost. This is modeled with a risk neutral value function for the supplier.

We suppose that $p-c-\gamma-a \geq 0$, so that the first period return on the widget market is at least sufficient to invest $a$ in the relationship with a supplier. Hence, the constraint on the buyer's access to a bank loan does not prevent him from investing in the project.

We next show how a long term binding contract between the buyer and a supplier can offer dividend smoothing to the buyer and deal optimally with the hold-up situation. The first best long-term trade solution is such that the supplier offers a long-term financing plan for the adjustment paid in period 0 for his own product. Therefore, vendor financing could be an efficient alternative for credit constrained businesses if contracts were perfect. When, for whatever reason, long-term binding contracts are unavailable, we then find a self-enforcing long term relationship that allows for imperfect financing from the supplier.

\section{$2.1 \quad$ A long term contract}

If the buyer and the supplier can commit for the entire horizon, a long-term optimal contract can be found in period 0 that deals optimally with the hold-up situation. It prescribes a sequence of transfers $\left\{\pi_{t}\right\}_{t=0}^{T}$ for all future periods that maximizes the buyer's value over the $T$ periods, under the constraint that the supplier's discounted payoff is at least equal to zero. The long term binding contract solves the following problem

$$
\max _{\left\{\pi_{t}\right\}_{t=0}^{T}} \sum_{t=0}^{T} \beta^{t} V\left(p-c-\pi_{t}\right) \quad \text { s.t. }-a+\sum_{t=0}^{T} \delta^{t}\left\{\pi_{t}-\gamma\right\} \geq 0 .
$$

Note that the buyer and the supplier do not have to share the same discount factor. We make no particular assumption on the relative sizes of the supplier's discount factor $\delta$, and the buyer's $\beta$. It is obvious that the optimal contract offers to the buyer a perfect smoothing of his dividend through a constant transfer. The transfer $\bar{\pi}$ is equal to the cost $\gamma$ of the intermediary good plus a compensation for the one time adjustment cost $a$ paid for by the supplier in the initial period. This compensation is the average value of $a$ over the $T$ periods, discounted at $\delta$, so that the supplier's intertemporal discounted profit is equal to zero:

$$
\bar{\pi}=\gamma+\frac{1-\delta}{1-\delta^{T+1}} a
$$


Hence, the long-term contract solution illustrates the optimal vendor financing relationship. If the buyer and the seller can commit to always honor the long-term contract's provisions, there is no reason why a deep-pocket supplier could not help her client finance a first period investment through a specifically tailored sequence of transfers.

In reality, however, the buyer and his supplier cannot necessarily commit into a long term contract. Both partners may have an interest to keep open the option of changing partner at any time. Moreover, when the elements involved in the production and marketing of widgets, including the intermediary good itself, are specific, the cost of executing a trade contract is very high, making long term contracts non enforceable. Nevertheless, there could exist a self-enforcing agreement that keep the buyer with the seller for a long period of time. At worse, the buyer has to revert to the competitive market in each period. The implication for the buyer financing is the question we address next.

\subsection{Self-enforcing relationship}

Suppose that the buyer chooses a different supplier in every period. The buyers therefore incurs the adjustment cost $a$ and pays the intermediary good's supplier the competitive price $\gamma$ in each period. Changing supplier every period is obviously sub-optimal. The incumbent supplier, that had the contract the period before, could offer the same price and make the buyer economize on the adjustment cost. Hence, she has an advantage over her competitors so that she can charge higher prices and still supply the good.

We solve for the equilibrium sequence of contracts that maximizes the buyer's intertemporal value and leaves each supplier with a zero profit over the length of her relationship with the buyer. The optimal sequence of contracts must be optimal starting in any period $t$. Thus, we solve for the optimal sequence of contracts starting with the last period contract.

At the beginning of period $T$, the price for the intermediary good on the competitive market is $\gamma$. Trading with a new supplier would force the buyer to adjust his production process at cost $a$, so that his dividend would be $d_{T}=p-c-\gamma-a$. Hence, the incumbent supplier (who supplied the good in period $T-1$ ) can charge a price $\pi_{T}=\gamma+a$ and still be the chosen supplier for period $T .{ }^{4}$ Hence, the supplier in the last period is the same as in the period before. The buyer's value in this last period is $V(p-c-\gamma-a)$.

\footnotetext{
${ }^{4}$ We suppose that being indifferent between the prices charged by the incumbent supplier or her competitors, the buyer chooses to deal with the incumbent
} 
In period $T-1$, any supplier knows that if she gets the contract in $T-1$, she will be able to keep it as well in period $T$ and charge $\pi_{T}=\gamma+a$. Hence, the competitive price charged in period $T-1$ is $\tilde{\pi}_{T-1}$ such that

$$
\tilde{\pi}_{T-1}-\gamma+\delta a=0
$$

The competitive price in period $T-1$ is then $\tilde{\pi}_{T-1}=\gamma-\delta a$.

However, the incumbent supplier in period $T-1$ can offer $\pi_{T-1}=\gamma-\delta a+a$ and still have the contract because it allows the buyer to save on the adjustment cost $a$. Hence, the supplier that had the contract in $T-2$ remains the supplier in $T-1$ and $T$ and pockets the discounted sum of $T-1$ and $T$ profits:

$$
\Pi_{T-1}=a-\delta a+\delta a=a
$$

Suppose the same supplier can trade with the buyer in each period after $t$ with transfers equal to $\pi_{\tau}=\gamma+a-\delta a$ for all $\tau=t+1, t+2, \cdots, T$. That supplier pockets a rent of $(1-\delta) a$ every period that leaves her with a discounted profit $\Pi_{t+1}=\sum_{i=0}^{T-t-2} \delta^{i}(1-\delta) a+\delta^{T-t-1} a=a$. In period $t$, the optimal contract for the buyer is the one obtained on the competitive market where the supplier that obtains the contract will keep it until $T$. The binding participation constraint for the supplier, $\tilde{\pi}_{t}-\gamma+\delta \Pi_{t+1} \geq 0$, with $\Pi_{t+1}=a$, gives the competitive transfer price in $t$ as $\tilde{\pi}_{t}=\gamma-\delta a$. Consequently, the incumbent supplier at $t$ can offer the same contract to the buyer with transfer $\pi_{t}=a+\tilde{\pi}_{t}$ and still remain the supplier until $T$.

In period 0, there is no incumbent supplier. Since the supplier that receives the contract in $t=0$ can maintain her relationship with the buyer until $T$ and secure a payoff valued $\delta a$ in period 0 , competition induces all suppliers into proposing a rebate of $\delta a$ in period 0 . The transfer in $t=0$ is then $\pi_{0}=\gamma-\delta a$, and the discounted total payoff from the contract for the supplier is $\Pi_{0}=0$. Based on this reasoning, we find the following result for the procurement contract of the intermediary good.

Result 1 The buyer maintains his relationship with the same supplier over the $T$ periods. The price paid for the intermediary good in period $t$ is $\pi_{t}$ with

$$
\begin{aligned}
& \pi_{0}=\gamma-\delta a \\
& \pi_{t}=\gamma+(1-\delta) a \quad \text { for all } 0<t<T ; \\
& \pi_{T}=\gamma+a .
\end{aligned}
$$


The incumbent supplier charges $(1-\delta) a$ over the competitive price from $t=1$ to $t=T-1$ and she charges $a$ over the competitive price in the last period. Looking at the contract in any period $t>0$, it may appear as if there is a rent $(1-\delta) a$ collected by the supplier. This rent is generated by the hold up situation introduced by the existence of adjustment costs. Nevertheless, since there is competition on the market for the intermediary good, suppliers are willing to offer a first period rebate in order to secure the contract. This rebate of $\delta a$ makes the discounted value of the $T$ period trade relationship equal to zero in period 0 for the supplier. The equilibrium trade relationship is not the repeated transfer of the reserve price $\gamma$. The specificity of the intermediary good induces the supplier into offering a rebate $\delta a$ in the first period. She then secures a payments higher than the market price $\gamma$ in all subsequent periods.

This timing of payments perfectly resembles a trade credit relationship. It is as if the amount $\delta a$ was lent every period and repaid the next, at a constant rate $r=1 / \delta-1$. The amount $\delta a$ extended in the first period by the supplier partly finances the buyer's initial period investment $a$. The buyer then owes $a$ the next period. The sequence of transfers is such that the debt is rolled over from period to period as long as the relationship lasts. The buyer borrows $\delta a$ in one period to help with the payment of $a$ that he owes from the preceding period. In the last period, the buyer must reimburse the total due $a$. In other words, the buyer borrows each period an amount that allows him to delay the payment of the entire first period investment until the end of the relationship.

The size of the hold-up situation, measured by parameter $a$, has no influence on the implicit rate of financing. That is, the price of trade credit only depends on the supplier's discount rate $\delta$, that is dependent on her cost of funds $r=1 / \delta-1$. Competition among suppliers drives the price down to the competitive price $r$. Even if the buyer had access to credit at a rate lower than $r$, the hold-up situation would force him to accept this financing arrangement at the supplier's rate $r$.

Although switching costs cannot explain the implicit high interest rate that is observed in some trade credit two-part contracts. The size of the adjustment cost is related to the amount a supplier can lend to her customer. Indeed, since the buyer is not committed to a long-term relationship with the supplier, he could leave anytime without paying his due and buy from another supplier; the adjustment cost is the only parameter that holds him in the relationship with the supplier. The higher this cost, the more held up he is, and the more financing the supplier can extend in the first period without risk of default. Hence, we 
should expect vendor financing to be used more significantly in industries where suppliers and clients are in more symbiotic relationships.

\section{Financing investment}

We showed in the previous section of the paper that vendor financing allows to delay the burden of the initial investment $a$ towards the end of the relationship. The trade relationship would have an even greater interest if it could allow for the financing of other types of investments, like productive investments. It is obvious from Result 1 that there is no way of having the supplier lend an amount greater than $\delta a$ in the first period. The supplier has incentives to lend this amount only because becoming the first period supplier allows her to use her hold-up opportunity to charge up to $(1-\delta) a$ above the market price in future periods.

Standard contract theory establishes that if investment is non verifiable, as is the case when investment is made in specific technologies observable by the buyer and the supplier but not by an outside party, no debt contract can be written based on this investment. Hence, assuming a supplier can finance a productive investment in the buyer's firm, the buyer will reimburse the due amount only if it is in his interest to do so. It is, then, sensible to question if the threat of having to pay a to change supplier is sufficient to deter the buyer from reneging on his reimbursement. The threat is indeed sufficient only if the due reimbursement does not exceed $(1-\delta) a$. Hence, the best the supplier can offer as a first period loan is $\delta a$, which amounts to the financing of the project itself.

This limited amount $\delta a$ can make an appreciable difference for a small business, however. In our riskless environment, the buyer is especially concerned with the smoothing of his dividend. Having no access to credit, he welcomes any option to spread evenly costs and revenues across the horizon. The opportunity of a period zero financing of $\delta a$ allows the buyer to reach a more desirable plan of investments in any sector of his business. We see in this Section to what extent transfers with the supplier can ease generic productive investments.

Suppose the buyer can invest an amount $i \in[0, \infty)$ to increase the productivity of his project. The investment decreases the marginal cost of production that can then write $c(i)$ with $c(0)=c, c^{\prime}(i)<0$ and $c^{\prime \prime}(i)>0$. Investing in period 0 can increase productivity in every subsequent period. Let us denote $W_{t}$ the buyer's revenue before cost of production 
and investment. ${ }^{5}$ The optimal choice of investment in period 0 largely depends on the path $\left\{W_{t}\right\}_{t=0}^{T}$ because it must satisfy the double objective of increasing the firm's returns and smoothing the owner's dividend. The optimal investment solves

$$
\max _{i \geq 0} V\left(W_{0}-c(i)-i\right)+\sum_{\tau=1}^{T} \delta^{\tau} V\left(W_{\tau}-c(i)\right) .
$$

The first order condition for the choice of $i$ writes

$$
V^{\prime}\left(d_{0}\right)=-\sum_{\tau=0}^{T} \delta^{\tau} V^{\prime}\left(d_{\tau}\right) c^{\prime}(i)
$$

with $d_{0}=W_{0}-c(i)-i$ and $d_{\tau}=W_{\tau}-c(i)$ for all $\tau>0$.

The optimal investment must equate marginal cost and marginal benefits. On the lefthand side member of condition (3), we have the marginal cost of investing, incurred in period 0 . The marginal benefit, on the right-hand side member, is the discounted sum of the effect of a reduction of marginal cost $c^{\prime}(i)$ in each of the $T$ periods. Marginal costs and benefits in each period are weighted by the marginal value of the firm in the period, $V^{\prime}\left(d_{\tau}\right)$.

The effect of vendor financing shows through the size of $W_{\tau}$ that affects the weight $V^{\prime}\left(d_{\tau}\right)$. Suppose the buyer must pay for the adjustment cost in period 0 and only pays the reserve price $\gamma$ afterwards. In that case, the dividend in period 0 is very low. It is obvious that his marginal utility for period 0 dividend is much higher than the marginal utility for any subsequent dividend. The weight imposed on marginal cost limits the amount invested in productivity.

With switching costs, however, the buyer and the supplier can build a self enforcing long term agreement in which the buyer benefits from the initial funding $\delta a$. His dividend in period 0 is then equal to the dividends in the next periods, except for the last period that is more heavily weighted, but also highly discounted. In that case, the investment in productivity is much higher in the first period, increasing the buyer's return in the future. Vendor financing, even if not explicitly used to finance a specific project, provides working capital used to smooth the buyer's revenue. This, in turn, allows him to optimally invest in other projects without having to apply for bank debt.

Hence, the existence of a hold-up disadvantage for the buyer ends up being an opportunity to be offered financing, although at an inefficient level. It is often the case in financial

\footnotetext{
${ }^{5}$ For instance, $W_{t}=p-\gamma-(1-\delta) a$ at the solution in the preceding Subsection.
} 
contracting that the parties would like to be able to commit ex-ante in long term contracts even if they are unable to do so ex-post. Here, the switching cost acts as an imperfect binding mechanism that allows buyers to partly rely on vendor financing to optimally manage their working capital.

The trade credit literature raises the puzzle that trade credit offered through two-part contracts is very expensive. ${ }^{6}$ In our simple model, we find that vendor financing is extended by firms at their own cost of financing. This model cannot explain why firms that are offered generous discounts for early payment would refuse the opportunity. In our case, the desire of a smooth consumption makes the customer pay early with a rebate and obtain such a rebate in all periods. We interpret the discount as a loan instead of seeing a late payment as a form of borrowing. In our view, the firm can be offered generous discounts as long as the relationship has a future value for the supplier. Empirical studies should find evidence that customers who take the rebates are the ones with the longest and tightest relationships with their supplier. A short term view of the problem argues that the customer needs bank financing to be able to pay early and benefit from the discount. We would rather argue that the discount itself is a form of long term financing enabled by a symbiotic relationship between the buyer and the seller. Further empirical studies should test that the discount, when taken by the customer, is repeatedly taken and associated with the trade of a specific good.

\section{Conclusion}

For a small business with a restricted access to credit, it is overly important to be able to smooth the first period cost of finding a supplier. Here, competition among suppliers and switching costs allow the buyer to borrow from his supplier in period 0 and to roll over the debt from period to period until a late reimbursement in the final period of the relationship. Hence, a limited long term financing is possible when the firm can at least partially precommit in the relationship.

Where trade credit is often studied as short term financing between a buyer and his supplier, we show here that the financing relationship can be long term. In this paper, we

\footnotetext{
${ }^{6}$ Such contracts offer a rebate if a payment is made early, that is before a discount date, and give a net date for final payment if the discount is not taken. In its most common form, the discount is $2 \%$ and the net date is 30 days. For the buyer, refusing the discount amounts to borrow until the net date at a rate equivalent to an annual $45 \%$.
} 
find that the cost of finding a supplier in any period is the variable that influences the degree of commitment of the customer into a trade agreement. This cost generates its own partial financing in guaranteeing a future reimbursement. The existence of an adjustment cost that binds the buyer in a relationship with the same supplier for many periods is the opportunity to generate a first period financing that can be repaid in the future with no need of a binding long term contract. A debt is rolled over from period to period as long as the relationship has a future. When there is no horizon to the trade, the customer ends up paying the amount borrowed at the start.

The result is based on the hypothesis that the buyer is a small business with a need for a smoothing of his dividend. However, for a small business, managing liquidity shocks is as important as smoothing the cost of investments. Hence, a natural second step in a work on trade credit is to introduce risk in the buyer's revenue. It seems obvious that the trade relationships can manage risk-sharing as naturally as it manages first period loans. In the literature on self-enforcing risk-sharing relationships started with the paper by Thomas and Worrall (1988), it has become obvious that outside opportunities of the parties control their incentives to breach the contract as in Gobert and Poitevin (2006). Hence, the higher the switching cost to another partner, the easiest the enforcement of the contract. Risk sharing through trade relationship can then be made more efficient when adjustment costs are higher. It seems to us that the next stage on a research on small business and trade credit will be to study the limit to risk sharing imposed by enforcement capabilities.

Most results in the literature assume that a firm that pays early in order to receive an early discount does not borrow through trade credit. We show that, in a repeated context, the interpretation goes the other way. The discount can be seen as a first period lending in a long lasting relationship. This involves new openings for empirical testing. Long lasting trade relationships and the use of early discounts can be related to the specificity of the relationship between the buyer and the supplier.

Our model can explain why credit terms, that determine the implicit rate of trade credit, do not vary with the market interest rate. As we have showed, the discount offered in trade credit is dependent on the supplier's negotiation power (through switching costs) as well as on the creditor's discount factor. As long as the latter in not linked to the market rate, so are the trade credit terms.

Finally, because of the terms of some standard short-term financing contracts, trade credit is often mentioned as being very expensive. Nevertheless, theory so far could not 
justify such a high price and empirical surveys report that there is no evidence that the cost of trade credit is as high as what the two-part terms let us believe (Ng, Smith and Smith, 1999; Marotta, 2005; Burkart, Ellingsen and Giannetti, 2006). We show in our paper that transfers between the parties are such that the client borrows in each period an amount from the supplier at a rate implied by the discount rate of the supplier. Hence, trade credit is costly for the client only if he could have access to funds at a lower rate from a bank. This is rarely the case for small businesses that are more likely to be constrained on bank credit. 


\section{References}

1. Biais, B. and C. Gollier (1997). Trade Credit and Credit Rationing. Review of Financial Studies, 10(4): 903-937.

2. Boyer, M., M.M. Boyer and R. Garcia (2005). The Value of Real and Financial Risk Management. CIRANO Working Paper 2005s-38.

3. Brennan, M., V. Maksimovic and J. Zechner (1988). Vendor Financing. Journal of Finance, 43: 1127-1141.

4. Burkart M. and T. Ellingsen (2004). In-Kind Finance: A Theory of Trade Credit. American Economic Review, 94(3): 569-590.

5. Burkart M., T. Ellingsen and M. Giannetti (2006). What you Sell is What you Lend? Explaining Trade Credit Contracts. ECGI Finance Working Paper 71/2005.

6. Campbell T.S. and W.A. Kracaw (1987). Optimal Managerial Incentive Contracts and the Value of Corporate Insurance. Journal of Financial and Quantitative Analysis, 22: 315-328.

7. Cuñat, V. (2007). Trade Credit: Suppliers as Debt Collectors and Insurance Providers. Review of Financial Studies, 20: 491-527.

8. DeMarzo, P. and D. Duffie (1995). Corporate Incentives for Hedging and Hedge Accounting. Review of Financial Studies 8: 743-771.

9. Demirgüç-Kunt, A. and V. Maksimovic (2001). Firms as Financial Intermediaries. Evidence from Trade Credit Data. The World Bank, Policy Research Working Papers Series : 2696.g

10. Danielson, M.G. and J.A. Scott (2000). Additional Evidence on the Use of Trade Credit by Small Firms: The Role of Trade Credit Discounts. Mimeo, Temple University.

11. Elliehausen, G.E. and J. D. Wolken (1993). The Demand for Trade Credit: An Investigation of Motives for Trade Credit Use by Small Businesses. Board of Governors of the Federal Reserve System, Staff Studies Series 165.

12. Emery G.,W. and N. Nayar (1998). Product Quality and Payment Policy. Review of Quantitative Finance and Accounting 10(3): 269-84.

13. Ferris, J.S. (1981) A Transactions Theory of Trade Credit Use. Quarterly Journal of Economics 96(2): 243-270.

14. Frank, M. and V. Maksimovic (1998). Trade Credit, Collateral, and Adverse Selection. Mimeo, University of Maryland.

15. Gobert, K. and M. Poitevin (2006). Non-Commitment and Savings in Dynamic RiskSharing Contracts. Economic Theory 28(2): 357-372.

16. Graham, J.R. and D.A. Rogers (2002). Do Firms Hedge in Response to Tax Incentives? Journal of Finance 57: 815-839. 
17. Graham, J.R. and C.W. Smith (1999). Tax Incentives to Hedge. Journal of Finance 54: $2241-2262$.

18. Jain, N. (2001). Monitoring Costs and Trade Credit. The Quarterly Review of Economics and Finance 41: 89-110.

19. Kiholm Smith, J. (1987). Trade Credit and Informational Asymmetry, Journal of Finance, 42: 863-872.

20. Long, M.S. , I.B. Malitz and S.A. Ravid (1993). Trade Credit, Quality Guarantees, and Product Marketability. Financial Management 22: 117-27.

21. Marotta, G (2005). When Do Trade Credit Discounts Matter? Evidence from Italian Firm-level Data. Applied Economics 37: 403-416.

22. Nance, D.R., C.W. Smith and C.W. Smithson (1993). On the Determinants if Corporate Hedging. Journal of Finance 48: 267-284.

23. Ng, C.K., J. Kiholm Smith and R.L. Smith (1999). Evidence on the Determinants of Credit Terms Used in Interfirm Trade. Journal of Finance, 54: 1109-1129.

24. Niskanen, J and M. Niskanen (2006). The Determinants of Corporate Trade Credit Policies in a Bank-dominated Financial Environment: the Case of Finnish Small Firms. European Financial Management, 12(1): 81-102.

25. Petersen M. A. and R. G. Rajan (1997) Trade Credit: Theories and Evidence. Review of Financial Studies 10(3): 661-691.

26. Rajan, R.G. and L. Zingales (1995). What Do We Know About Capital Structure? Some Evidence from International Data. Journal of Finance, 50: 1421-1460.

27. Santos, J.A.C. and S.D. Longhofer (2003). The Paradox of Priority. Financial Management, 32 no. 1: 69-81.

28. Smith, C.W. and R. Stulz (1985). The Determinants of Firms' Hedging Policies. Journal of Financial and Quantitative Analysis 20: 391-405.

29. Smith, J. K. (1987). Trade Credit and Informational Asymmetry. The Journal of Finance, 42(4): 863-872.

30. Stulz, R.M. (1984). Optimal Hedging Policies. Journal of Financial and Quantitative Analysis, 19: 127-40.

31. Thomas, J. and T. Worrall (1988). Self-enforcing Wage Contracts. The Review of Economic Studies 55: 541-544.

32. U.S. Small Business Administration (1994). Bridging the Valley of Death: Financing Technology for a Sustainable Future. Report prepared for the U.S. Environmental Protection Agency, Interagency Agreement \#DW73936877-01, 107 pages. 